\title{
Encontros feministas e as possibilidades da política*
}

\author{
Thiago Ranniery Moreira de Oliveira**
}

Só poderia haver um encontro de seus mistérios se um se entregasse ao outro: a entrega de dois mundos incognoscíveis feita com a confiança

com que se entregariam duas compreensões.

Clarice Lispector (1998:167)

Evocar Clarice Lispector em uma epígrafe para esta resenha - que tem por objetivo apresentar o livro Despossession: the performative in the political e mostrar como vejo e significo essa obra - implica um ponto de partida. Significa tomar a poética do encontro, tão densamente explorada por Lispector no conto As águas de mundo para saber o que acontece quando dois ou mais corpos, não necessariamente propriedades identificáveis, se encontram em uma secreta amizade. Essa frase é usada, aqui, porque aborda uma dimensão que tem se feito presente nas múltiplas trajetórias dos estudos feministas: o encontro ${ }^{1}$ (Buchana; Colebrook, 2000). Encontro é, de fato, a palavra-chave para Despossession. É no encontro que seu corpo se materializa. Seu escopo advém de uma reunião entre uma das mais influentes filósofas feministas do nosso tempo e uma potente voz emergente

\footnotetext{
* Recebida para publicação em 29 de outubro de 2014, aceita em 29 de julho de 2015. Resenha de ButLER, Judith; AthANASIOU, Athena. Despossession: the performative in the political. Cambridge, Polity Press, 2013.

** Universidade do Estado do Rio de Janeiro, Rio de Janeiro, Brasil. t.ranniery@gmail.com

1 Butler não é mesmo nenhuma neófita em compor livros com formato de diálogo colaborativo. Para ficar com dois conhecidos exemplos, ver a parceria com Ernesto Laclau e Slavoj Zizek (2000) e o livro escrito com Spivak (2011).
} 
da teoria feminista contemporânea: Judith Butler, conhecida entre nós por sua frente de exploração da performatividade de gênero, que remonta ao clássico Gender Trouble, e Athena Athanasiou, uma jovem pesquisadora do Departamento de Antropologia Social da Universidade Panteion na Grécia. Juntas examinam a despossessão $^{2}$ no contexto de intensificação do regime de endividamento que se seguiu à crise financeira global de 2008 para explorar as potencialidades da performatividade da política.

Em 2011, durante os meses turbulentos em que protestos se espalharam da Praça Tahrir, no Egito, para Zuccotti Park, na Grécia, Butler e Athanasiou envolvem-se em uma conversa que ocorreu, em grande parte, mas não exclusivamente, via e-mail, para explorar as múltiplas valências do conceito de despossessão em relação à força performativa dos corpos quando reunidos em protesto. Despossessão, argumentam elas, tem que ser pensada não apenas como uma condição de privação, mas também como uma exposição à alteridade. Nesse sentido, adquire uma dimensão que permite perturbar a fantasia do sujeito autossuficiente e iluminar o aspecto constitutivo da relacionalidade nos processos de subjetivação. O livro, escrito como um diálogo que se desdobra em capítulos curtos, complica o debate atual sobre as novas formas de coletividade que emergiram das ruas, especialmente por meio dos modos de organização feministas e de estados pós-coloniais.

Duas obras importantes vêm à mente quando se pensa em despossessão. A primeira é a The Politics of Dispossession de Edward Said (1994), que tenazmente documenta a resistência palestina, apesar das perdas de território e das violações aos laços sociais perpetrados pela consolidação do colonialismo israelense. A segunda é a reflexão de David Harvey (2004) sobre "acumulação por espoliação", um conceito que se baseia na

\footnotetext{
2 Traduzi, aqui, despossession por despossessão ao invés de espoliação ou desapropriação, como tem sido feito com outros autores que trabalham com o conceito, em virtude desses últimos termos não permitiremm abarcar a amplitude da crítica de Judith Butler e Athena Athanasiou.
} 
formulação de Karl Marx (2013) sobre acumulação primitiva. Enquanto para Marx o cercamento de terras na Inglaterra do século XVI, que transformou camponeses em operários assalariados, foi um estágio circunscrito e necessário da transição do feudalismo para o capitalismo, Harvey afirma que, sob regimes neoliberais atuais, desapropriação de terras e recursos e violações de bem-estar ocorrem de forma contínua e em escala global. Porém, enquanto Said e Harvey fornecem um quadro que destaca a dimensão forçada e material da despossessão, Butler $e$ Athanasiou estão interessadas em explorar uma nuance suplementar, mas igualmente importante, e que, poderíamos chamar sem nenhum prejuízo, à esteira de outro livro de Butler (1997), de "vida psíquica" da despossessão. Com efeito, as autoras centram-se em tecer esses dois aspectos em conjunto através do modo pelo qual as políticas performativas permitem a emergência, do que chamam, de formas de agência crítica.

No coração dessa conversa, em particular na primeira parte do livro, está a ambivalência da despossessão e sua natureza perturbadora. Em um primeiro plano, Butler e Athanasiou sugerem que ser despossuído refere-se aos processos complexos de abjeção que produzem a distribuição diferencial da vulnerabilidade e do sofrimento na paisagem geopolítica. Nesse sentido, a desapropriação refere-se à perda das terras, do senso de comunidade, da situação jurídica e dos direitos ligados a essas situações. Mas também se refere à privação da autodeterminação corporal $e$ à exposição à experiência de normas de sexo, gênero $e$ parentesco que determinam quais corpos configuram como vidas dignas de serem vividas. Numa segunda instância, despossessão designa a condição fundamental da interdependência e da relacionalidade que marca a emergência da condição humana. Como Butler e Athanasiou insistem, qualquer um de nós já está sempre despossuído pelo encontro com o outro, o que sinaliza os limites da autossuficiência do sujeito.

De certa forma, despossessão envolve expor as ruínas do sujeito humanista com o poder pleno de apropriar-se do mundo ao seu redor, pois é o deslocamento constitutivo do "eu" que 
promove a liga do como viver juntos. Dessa perspectiva, nomear despossessão como aquilo nos impulsiona além de nós mesmos pode servir de recurso político na medida em que aponta para capacidade de agência como ação coletiva. Nesse ponto, algumas dúvidas emergem: o que torna possível responder à condição de despossessão? Como é que se passa da despossessão para engajamento ético e político? Entre as indicações com tom de preliminares, uma parece especialmente intrigante: a necessidade de uma abordagem da despossessão que mantenha seu aspecto material sem buscar recurso à lógica da propriedade individual neoliberal. Essa questão é particularmente importante para a política feminista na medida em que chama a atenção para os limites do discurso de posse do corpo articulado através do slogan "o corpo é meu". Butler e Athanasiou deixam claro, contudo, que o ponto da crítica não é descartar as reivindicações feministas de autodeterminação e autonomia, mas dar conta das aporias que as subscrevem.

Uma das instigantes provocações colocadas é como reformular essas reivindicações fora da lógica da individualidade proprietária de si mesmo, gestada no século XVII, na qual o indivíduo livre é o dono de seu próprio corpo e detentor de suas capacidades. Talvez, aqui, se possa lamentar que Butler e Athanasiou não depreendam muito tempo discutindo os envolventes debates feministas sobre propriedade. Esse é um limite do livro, que se move um pouco rápido demais mesmo quando tenta cobrir um terreno muito amplo. Por vezes, a sensação é de que Butler e Athanasiou estão a discutir suas ideias durante uma conferência em ritmo eletrizante. Essa forma dialógica pode provocar a sensação de restringir a profundidade que a conversa poderia ir. Prefiro, todavia, imaginar que são insights, pequenas fulgurações, que, se poderiam ser elaboradas em formato de livro por si mesmas, assim expostas, mantêm o frescor da provocação. Não duvido que aqueles familiarizados com Butler e Athanasiou, talvez possam ansiar que o livro se desdobre em um projeto maior. Por outro lado, o tom de conversa se presta para aqueles não familiarizados com os trabalhos 
anteriores das autoras e, enquadrando a conversa dentro das crises políticas atuais, posiciona a despossessão como uma potente ferramenta para manifestantes e ativistas.

A segunda metade do livro se move da exploração da despossesão para o terreno da performatividade. Como muito do trabalho anterior de Butler já mostrou, a política da performatividade invoca e, ao mesmo tempo, desafia as normas que produzem e regulam corpos raciais, sexuados e de gênero. Políticas performativas ocorrem quando aqueles que não contam como vivíveis para uma comunidade política afirmam suas incontornáveis presenças e o direito de existir. $\mathrm{O}$ esforço de Butler e Athanasiou de pensar a desposessão em relação a performatividade vem, em parte, inspirado pelas manifestações que formam parte de qualquer balanço do cenário político mundial desde o final de 2010. Fazem, assim, inúmeras referências a mobilizações políticas, como acampamento em Tahrir, a ocupação de Syntagma Square no centro de Atenas, o Occupy Wall Street e as lutas pela educação pública na Europa. A ampla gama de referências que pontuam as páginas de Despossession população indígena da Austrália, o conflito Israel-Palestina, os sujeitos LGBT, colonização do norte da África, mulheres no sul da Ásia - pode tornar o livro um pouco denso para o leitor/a desavisado/a. E, se pode parecer que querem criticar todas as injustiças através de lentes temporais bastante estreitas, logo no início, Butler adverte contra a sublimação de histórias particulares.

As autoras estão, portanto, atentas às diversas reivindicações, práticas e especificidades históricas de seus exemplos. Todavia, sua argumentação ressalta que esses movimentos têm uma série de características comuns: a transformação dos espaços públicos, a recusa da representação $e$ a articulação de formas de democracia radical. Uma série de teóricos políticos, como Michael Hardt e Antonio Negri (2012), Jodi Dean (2012) e Alain Badiou (2012), tem respondido a essas manifestações girando em torno de temas como organização $e$ demandas. Butler e Athanasiou sugerem, à contramão, que essas intervenções mostram como a performatividade funciona como 
uma política. Corpos quando agenciados em público podem não articular um conjunto preciso de demandas e, ainda sim, performarem uma demanda pelo fim das condições de precariedade e despossessão que tornam a vida insuportável. Ao mesmo tempo, performam uma forma de vida caracterizada por relações que produzem precariedade. Em outras palavras, chamam a atenção para a desigualdade estrutural e indicam possíveis alternativas. Reunindo um trabalho já realizado por teóricas e críticas feministas sobre o conceito de reconhecimento, Butler e Athanasiou o articulam com questão da performatividade. Políticas performativas implicam sempre uma demanda de reconhecimento em formas institucionalizadas, mas também afirmam a possibilidade de modos de vida que ultrapassem os próprios termos de reconhecimento estabelecidos pelas instâncias reguladoras.

Butler e Athanasiou ofertam, assim, uma rara contribuição para o debate atual sobre os novos movimentos sociais, direcionando também a atenção para o papel desempenhado pelas políticas feministas na formação de modos de aliança comunitária que são, invariavelmente, corporais e afetivos. Realizam tal projeto de várias maneiras. Uma delas é questionando a tendência da esquerda em reafirmar a "primazia do econômico" (p.3) e oferecem valiosas pontuações sobre como gênero $e$ raça estruturam estados contemporâneos de endividamento e violência. Recordando os debates vigorosos entre Butler e Nancy Fraser da década de 1990, Athanasiou questiona a "ortodoxia economicista" (p. 39). Porém, com cuidado para não deixar de lado as questões econômicas, formula que "não há nada meramente econômico sobre a economia" (p. 39). Perturbar a hegemonia do capitalismo requer "abrir espaços conceituais, discursivos, afetivos e políticos para a ampliação de nosso imaginário econômico e político" (p. 40). Aqui podemos ver, o quão profundamente a concepção de biopolítica de Foucault informa suas críticas.

Além disso, Butler vê os protestos como os "espaços da aparência" de Hannah Arendt (2008), que emergem através da 
performance de atos e palavras e explicitam a condição humana da pluralidade. Todavia, contra Arendt, afirma que o borramento da distinção entre público e privado, algo caro à política feminista, é uma das principais características das manifestações. Juntas oferecem vários exemplos de como práticas e preocupações feministas específicas têm afetado os protestos. Referem-se, de modo especial, aos grupos feministas envolvidos na ocupação da Syntagma Squaree que criticaram as referências às polis gregas em virtude do fundamento da democracia antiga funcionar através da exclusão das mulheres e escravos. Assim, advertiram contra o risco de idealizar formas de pertença comunitária que, a despeito de invocarem a pluralidade, acabam pausterizando diferenças. Nesse ponto, a voz de Athanasiou retoma a importância de repensar os modos de viver em comum que não erradiquem, mas multipliquem diferenças. Seguindo Jean-Luc Nancy (2000), ela propõe imaginar a comunidade "como uma ocasião em que as pessoas partilham precisamente uma certa impossibilidade de serem-comum" (p. 117).

Athanasiou faz, de fato, um vigoroso trabalho de forçar Butler a esclarecer sua posição sobre uma série de tópicos, como os limites das políticas de reconhecimento e sua recorrência à obra de Hannah Arendt. As duas trazem seus estilos próprios e, de modo incisivo, jogam uma com a outra de forma emocionante. Todavia, não se pode deixar de notar que raramente existe desacordo. Às vezes, parece uma conversa sobre o trabalho de Butler, em vez de um encontro que provoca o pensamento. Além disso, na passagem da despossesão para as políticas performativas, algumas distinções correm o risco de se perder. Não é totalmente claro como o entendimento da despossessão é diferente da compreensão de precariedade, à qual Butler (2004a; 2009) tem se dedicado. Ambos os conceitos surgem a partir de um tema que lhe aparece valioso: a valorização da "improvisação dentro de uma cena de constrangimento" (Butler, 2004b:1). Ainda assim, há momentos em que se torna difícil saber como essas categorias divergem, se é que divergem, e se complementam. Quando Butler sugere que "o performativo emerge precisamente 
como o poder específico do precário - desautorizado pelos regimes jurídicos existentes, abandonado pela própria lei - para exigir o fim da sua precariedade" (p. 121), deixa em aberto se o mesmo poderia ser dito sobre os despossuídos.

Provavelmente, leitores fluentes da sua obra podem não encarar esse livro como particularmente inventivo. No entanto, oferece instigantes pontos de entrada para as práticas políticas contemporâneas. O encontro entre Butler e Athanasiou traz para a tona como a política feminista pode lançar um olhar localizado para compreender e abordar às políticas das ruas e dos protestos. A política da performatividade tanto convida ao questionamento crítico quanto desestabiliza o estilo de militância que muito da teoria política atual tem evocado. Essa conversação também faz um trabalho notável sobre a necessidade de conceituar despossessão fora da lógica da propriedade privada. Mas é, sobretudo, ao explorar o paradoxo da agência como uma possibilidade impossível que essa obra parece pertinente para uma leitura feminista das possibilidades da política. Despossession é um convite para discernir o quanto nossas teorias podem explorar essa ambivalência da performatividade e se, quando o fazem, podem proporcionar novas formas de encontrar alteridades. "Porque sabe - sabe que fez um perigo. Um perigo tão antigo quanto o ser humano" (Lispector, 1984:169).

\section{Referências bibliográficas}

ARENDT, Hannah. A condição humana. Rio de Janeiro, Forense Universidade, 2008.

BADIOU, Alain. The rebirth of history: times of riots and up risings. New York, Verso, 2012.

BUTLER, Judith. The pischic life of power. Stanford, Stanford University Press, 1997. . Precarious life. New York, Verso, 2004a. . Undoing gender. New York, Routledge, 2004b. . Frames of war. New York, Verso, 2009. 
; LaClau, Ernesto; ZizeK, Slajov. Contingency, Hegemony, Universality. New York, Verso, 2000. ; SPIVAK, Gaytrick. Who sings the Nation-State?. Chicago, University of Chicago Press, 2011.

Buchana, Ian; Colebrook, Claire (eds). Deleuze and feminist theory. Edinburgh, Edinburgh University Press, 2000.

DEAN, Jodi. The communist horizon. New York, Verso, 2012.

HARDT, Michael; Negri, Antonio. Declaration. New York, ArgoNavis, 2012.

HARVEY, David. O novo imperialismo. São Paulo, Edições Loyola, 2004.

LISPECTOR, Clarice. Felicidade Clandestina. Rio de Janeiro, Rocco, 1998.

MARX, Karl. Capital, vol. I. São Paulo, Civilização Brasileira, 2013.

NANCY, Jean-Luc. La comunidad inoperante. Santiago de Chile, Arcis, 2000.

SAID, Edward. The politics of dispossession: The struggle for Palestinian self-determination. New York, Pantheon Books, 1994. 